\title{
BIM FOR FACILITY MANAGEMENT: DESIGN FOR MAINTAINABILITY WITH BIM TOOLS
}

\author{
R. Liu ${ }^{1}$ and R. R. A. Issa ${ }^{2}$ \\ ${ }^{1}$ Construction Science and Management Program, College of Architecture, 501 W.César E. Chávez Blvd, \\ San Antonio, TX -78207; PH (210) 458-3054; email: rui.liu@utsa.edu \\ ${ }^{2}$ Rinker School of Building Construction, University of Florida, PO Box 115703, Gainesville, FL, USA \\ 32611-5703; PH (352) 273-1152; email: \\ raymond-issa@ufl.edu
}

\begin{abstract}
As Building Information Modeling (BIM) becomes widely adopted by the construction industry, it holds undeveloped possibilities for supporting Facility Management (FM). Some FM information systems on the market claim to address the needs for FM requirement. However, the question of whether the functionalities provided by the current BIM-based FM software companies are those actually required by the FM Professionals still need to be answered. The data is required by FM professionals in the operation and maintenance phases of facilities and type of maintainability problems that frequently occur, which can be solved early in design phase, have not yet been addressed. The aim of this paper is to clarify the frequently occurring maintainability problems and to investigate the potential areas that can use BIM technology to solve the maintenance problems in early the design phase. A survey was conducted to collect perspectives from the industry practitioners for the maintenance problems and their frequency. The survey results indicated that maintainability considerations should be taken into consideration during the facility design phase. The results also address the perceived areas by practitioners that need maintainability consideration in design phase.
\end{abstract}

Keywords: Building Information Modeling, Facility Management, Design for Maintainability 


\section{INTRODUCTION}

Facility managers are the ones who finally operate and maintain the designed and constructed buildings for years. There are many organizations and professional groups involve in these fields. The leadership of these organizations is only now beginning to communicate and collaborate. To date, however, they have not served the facility and property managers well (Cotts et al. 2010). On one hand, designers and constructors seldom know what documents and other varieties of information are needed for the facility management phase. On the other hand, only a limited degree of experience in the use and operation knowledge of these existing buildings is sent back to the design phase for consideration (Jensen 2008). The link between design and facility management is not sufficiently understood and is usually avoided (Erdener 2003). Hence, issues related to facility maintenance have been left out of the decisionmaking process (Pati et al. 2010).

With the development of BIM, knowledge sharing between the facility management and design professionals has become possible. However, different stakeholders in the AEC industry are currently still working in their own silos and are afraid to cooperate with each other since inadequate interoperability is still a problem. A study by the US National Institute of Standards and Technology (NIST) showed that the annual costs associated with inadequate interoperability among software systems was $\$ 15.8$ billion (Gallaher et al. 2004). Two thirds of this cost was incurred as a result of ongoing facility operation and maintenance activities (Shen et al. 2010).

Moreover, some design defects that make maintenance activities impossible to perform are always hard to foresee in the design phase even if BIM is used and the model has been run through clash detections. Foster (2011) noted that the largest building cost component over its life cycle is maintenance, which is ignored in the design phase and proposed that the next generation of advancement for Facility Management (FM) should be in "Design for Maintenance"(D4M).

\section{LITERATURE REVIEW}

Based on the different varieties of information encompassed by a building information model, researchers and industry practitioners can categorize it as an $\mathrm{n}-\mathrm{D}$ model (e.g.3D, 4D, 5D, and 6D models). 3D always refers to the three spatial dimensions of the building model, namely, the width, length and height. The scope of BIM extends beyond 3D to 4D, where the aspect of time is added to form schedules; and to $5 \mathrm{D}$, where the cost component helps create estimates. The $6 \mathrm{D}$ aspect, with project controls and life cycle management, is presently being developed (Luthra 2010). Some researchers (Qi et al. 2011, Zhang et al. 2012) also add the 7th dimension, such as integrating design for safety, based on OSHA regulations, into the BIM model. Regardless of what dimensions the BIM model may assume, all these aspects are simply efforts to apply more information and knowledge to the model, and thus improve integration and coordination in the AEC industry. However, the facility management phase, especially facility maintainability, has yet to be addressed in current BIM dimensions.

Erdener (2003) proposed the potential of programming as a link between design and FM, but did not provide a role for the facility manager in the integrated design environment. Mohammed and Hassanain (2010) described the role of a facility management team in the integrated design team.

Bröchner (2003) attempted to investigate avenues toward integrating facility design and service, assuming that economic efficiency is the ultimate goal in the facility owner's view. Knowledge transfer from building maintenance and operation to building design is not a new idea. Bröchner (1996) mentioned relevant experiments from Sweden in the 1960's, but the results were far from satisfactory. With the development of information technology, Bröchner expected that this knowledge transfer should become easier. He focused his study on a particular building and dispatched the feedback from operation to the design team that was responsible for this building.

The British Institute of Facilities Management (BIFM) commissioned a project to the BRE (Building Research Establishment), which was aimed at bringing facilities' expertise into the design process. They produced a report that analyzed why and when facilities management should be involved in the design phase, and why, in reality, they were not involved (Jaunzens et al. 2001). One of the main problems discussed was the fact that facilities managers are not sufficiently qualified and are not accepted as an equal dialogue partner in the design phase. In order to change the current status, which ignores 
facilities management in the design phase, their potential knowledge in the matter should be considered. Their insight could be vital to the design professionals.

Arditi and Nawakorawi (1999a, 1999b) claimed that 50\% of the maintenance related problems can be eliminated if design defects can be prevented during the design phase. When considered in the early design phase when flexibility is high and design change cost is low, product maintainability can eliminate maintenance costs, reduce downtime and improve safety (FitzGerald 2011). An effective Computerized Maintenance Management System (CMMS) should include the various aspects of maintenance management functions. In the construction industry, FM:Systems and Autodesk have released an interactive workplace management suite that can provide information about building mechanical equipment for preventive maintenance that is derived from the BIM model (FM:Systems 2010). Although the development of this suite is a good effort to connect BIM and FM, this platform does not consider the maintenance requirements in the design phase. If the facility manager's involvement can be brought into the design phase, major repairs and alterations in the lifespan of the facility will be reduced (Mohammed 2010).

It is difficult, however, to get the facility manager involved early on in the design phase because during the design phase, the facility management team may not have been set up yet. Thus bringing the facility management team's knowledge, such as facility maintenance requirement, through BIM, which does not require the physical presence of the facility management staff, can be a solution to this problem.

\section{PROPOSED PROCESS}

Although every construction projects have its own uniqueness, there is a big portion of knowledge that can be used as general knowledge. For example, for specific equipment, the accessibility for maintenance activities needs to be determined. Such knowledge can be saved in a general database carried by BIM library.

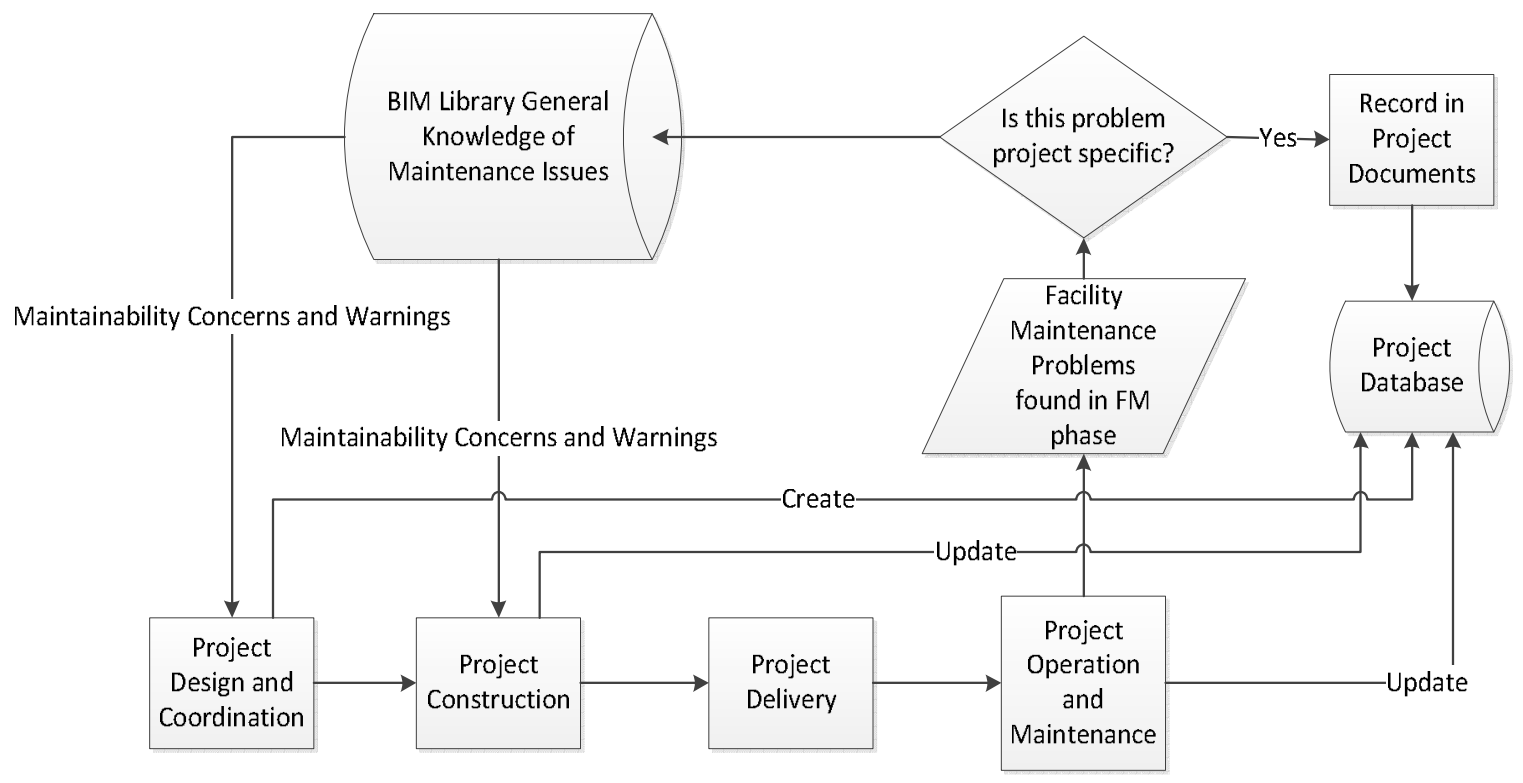

Figure 1- General Knowledge Database for Maintenance Issues

\section{THE SURVEY RESULT}

The survey was distributed in a variety of methods: (1.) through Stevens Construction Institute's newsletter, (2.) through LinkedIn groups related to FM including: Facility Managers Building Owners Network, Building Owners and Managers Association International (BOMA), and Integrated Facility Management (IFM), and (3.) through an email list, collected by the author, combined with COAA Owners from Higher education, K-12, government and some organizations. It was also distributed to the Florida State University System (SUS) facility management department. Through the first month only 12 
complete responses had been received. With the help of the buildingSmart Alliance, the survey was distributed again and there were 693 visits, 22 partial responses and 38 complete responses. Since it is not possible to determine the exact number of people who received the survey link because people who got it had the ability to forward it to anyone they thought suitable, the response rate can only be calculated based on the number of visits and the number of complete and partial responses. The response rate was $(38+22) / 693=8.66 \%$, while the effective response rate was $38 / 693=5.48 \%$.

\section{Part I: Demographic Distribution}

The respondents of this survey belonged to the organizations as shown in Figure 2. Different roles in the same company may have different perspectives and ideas. Figure 3 shows the distribution of the respondents' role in their companies including 14 upper managers $(36.8 \%)$, eight project managers and project engineers $(21.1 \%)$, five facility managers $(13.2 \%)$ and five architects (13.2\%). Management level respondents constituted two-thirds of all the responses.

The respondents' BIM experience ranged from "no experience" to "expert." Among the 38 respondents, only nine $(23.7 \%)$ considered themselves as experts, and five $(13.2 \%)$ defined themselves as advanced BIM users. Ten $(26.3 \%)$ of them described themselves as intermediate users. Nine $(23.7 \%)$ respondents classified their BIM experience level as beginners and five (13.2\%) of the respondents had no experience with BIM projects.

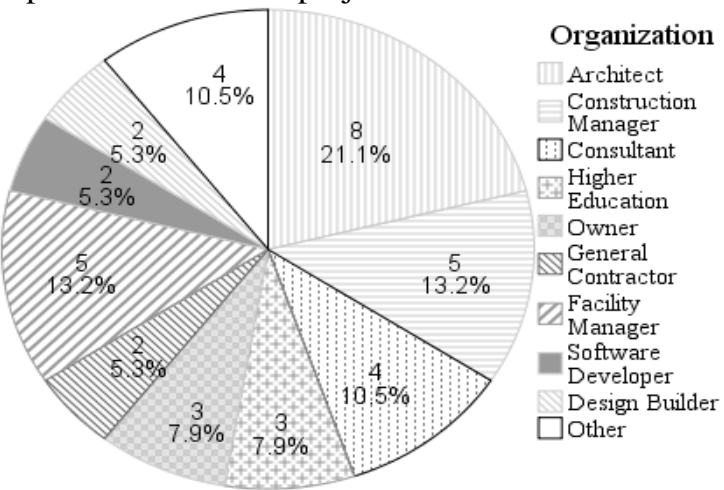

Figure 2- Respondents' organization

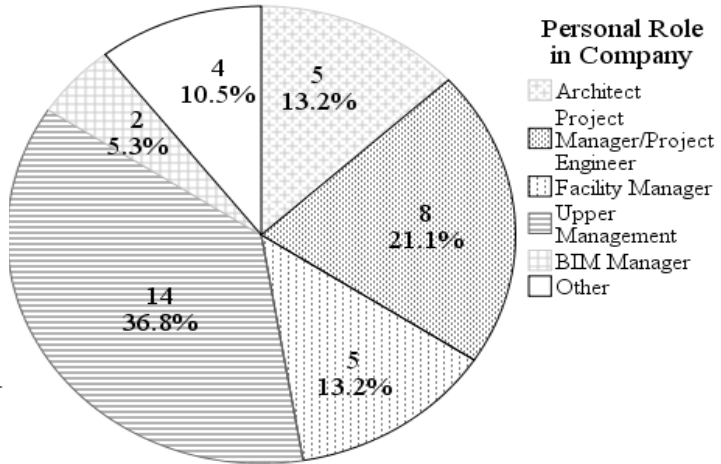

Figure 3- Respondents' Role in Company

In order to determine the objective BIM project involvement from the responses, the proportion of BIM projects among new projects in the past 12 months was calculated from the respondents' answers about their number of new projects and the projects that used BIM. As shown in Figure 4, among the 34 effective responses, seven respondents $(20.6 \%)$ had no BIM project for the last year. Seven of them $(20.6 \%)$ had less than $10 \%$ of their projects that utilized BIM. There were $12(35.3 \%)$ respondents who utilized BIM in all their new projects. From Figure 4, the BIM utilization of these companies is polarized. The company either uses BIM for all their projects or uses BIM for a very limited proportion of their new projects.

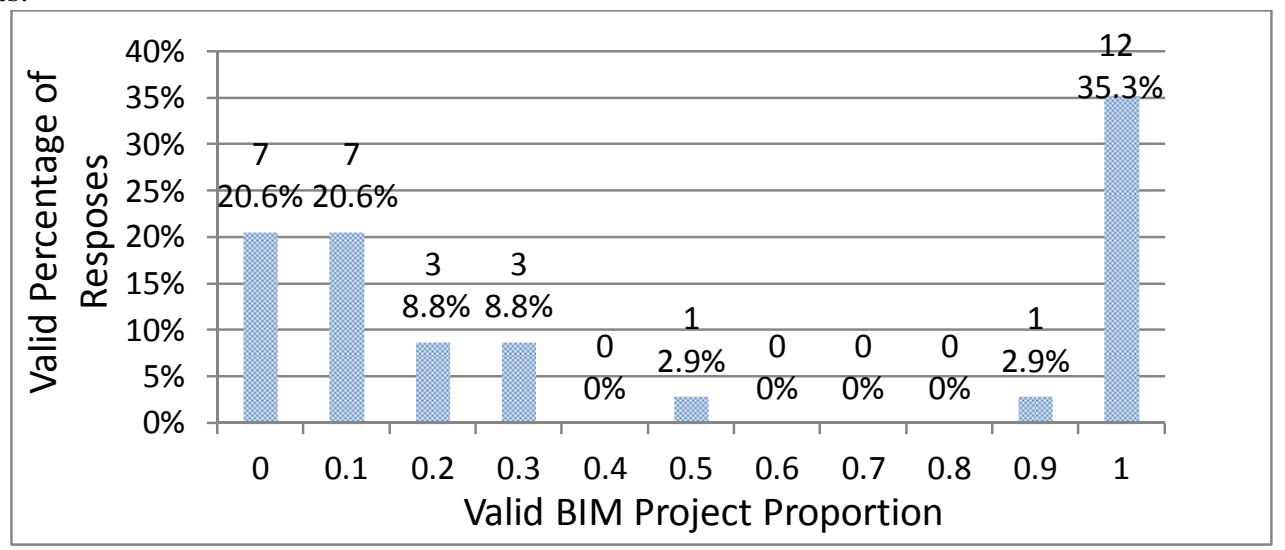

Figure 4- BIM project proportion 


\section{Part II: Maintainability Problems from Practitioner's Perception}

This survey was aimed at collecting the perceptions from people working in the AECO industry. Some responses from software developers and attorneys have been excluded, because their understanding of facility maintenance might not be consistent with AECO practices. As a result, for part II, there were 32 effective responses.

As shown in Figure 5, there were 32 effective responses as to whether maintainability was taken into consideration during the design and construction phases. Twenty-eight $(87.5 \%)$ of the respondents indicated that they have considered maintainability somewhat in the design and/or construction phases, while $20(62.5 \%)$ of them have considered it in both the construction and design phases. Only four $(12.5 \%)$ respondents had never experienced taking maintainability into consideration in the design and construction phases. From the responses, it seems that maintainability has already been thought of by most of the practitioners.

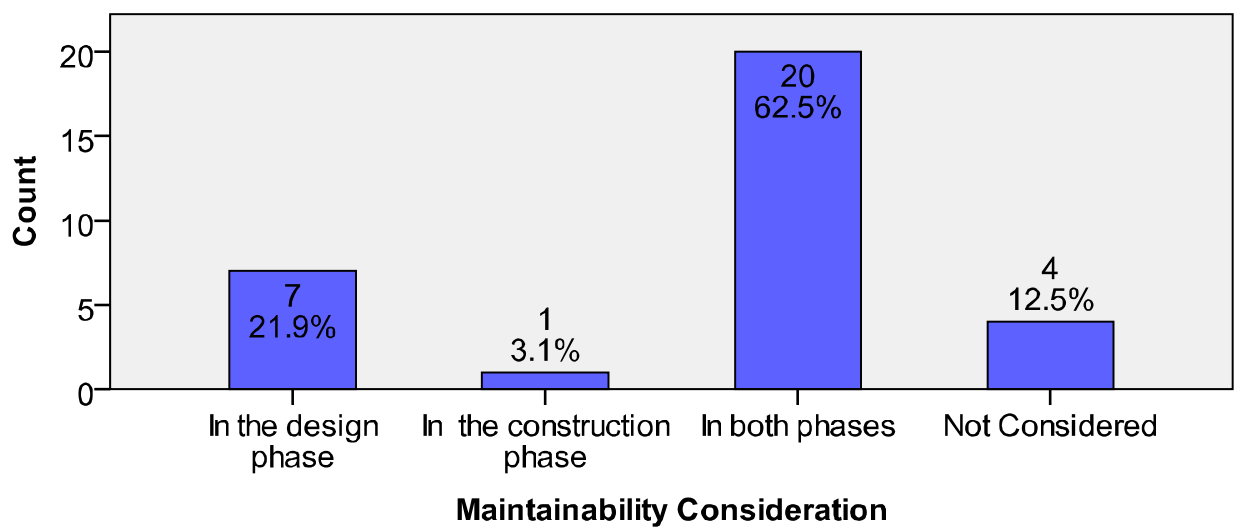

Figure 5- Construction phases that consider maintainability

The Pearson Correlation between organization types and maintainability is not significant at the 0.05 level $(0.197>0.05)$. There is no relationship between Organization type and maintainability consideration, which means that the answers from the respondents from different organizations about maintainability consideration were not significantly different.

For the design-related maintenance problems, the choices are from interviews of UF physical plants facility management personnel. Five problems were listed for the respondents to rate the frequency of each problem as shown in Table 1 (the respondents had the freedom to leave one or more problem blank, so the

Table 1. Maintainability problems based on frequency

\begin{tabular}{|c|c|c|c|c|c|c|}
\hline & Never & $\begin{array}{l}25 \% \text { of } \\
\text { the time }\end{array}$ & $\begin{array}{l}50 \% \text { of } \\
\text { the time }\end{array}$ & $\begin{array}{l}75 \% \text { of } \\
\text { the time }\end{array}$ & $\begin{array}{l}100 \% \text { of } \\
\text { the time }\end{array}$ & $\overline{\mathbf{N} / \mathbf{A}}$ \\
\hline & $\overline{1}$ & 2 & $\overline{3}$ & $\overline{4}$ & 5 & N/A \\
\hline Lack of equipment & 7 & 8 & 8 & 2 & 0 & 3 \\
\hline accessibility & $25.0 \%$ & $28.6 \%$ & $28.6 \%$ & $7.1 \%$ & $0.0 \%$ & $10.7 \%$ \\
\hline $\begin{array}{l}\text { Poor design of equipment } \\
\text { layout }\end{array}$ & $\begin{array}{l}3 \\
11.1 \%\end{array}$ & $\begin{array}{l}11 \\
40.8 \%\end{array}$ & $\begin{array}{c}8 \\
29.6 \%\end{array}$ & $\begin{array}{l}2 \\
7.4 \%\end{array}$ & $\begin{array}{l}0 \\
0.0 \%\end{array}$ & $\begin{array}{c}3 \\
11.1 \%\end{array}$ \\
\hline $\begin{array}{l}\text { Lack of adequate space for } \\
\text { mechanical room }\end{array}$ & $2.4 \%$ & $\begin{array}{l}10 \\
37.1 \%\end{array}$ & $\begin{array}{c}8 \\
29.6 \%\end{array}$ & $\begin{array}{c}5 \\
18.5 \%\end{array}$ & $\begin{array}{l}0 \\
0.0 \%\end{array}$ & $\begin{array}{l}2 \\
7.4 \%\end{array}$ \\
\hline $\begin{array}{l}\text { Lack of space designed in } \\
\text { the ceiling to contain MEP } \\
\text { systems }\end{array}$ & $\begin{array}{l}1 \\
3.7 \%\end{array}$ & $\begin{array}{c}7 \\
25.9 \%\end{array}$ & $\begin{array}{c}8 \\
29.6 \%\end{array}$ & $\begin{array}{c}5 \\
18.6 \%\end{array}$ & $\begin{array}{c}4 \\
14.8 \%\end{array}$ & $\begin{array}{l}2 \\
7.4 \%\end{array}$ \\
\hline Limited space for AHU & 5 & 7 & 7 & 4 & 0 & 3 \\
\hline filter access & $19.2 \%$ & $26.9 \%$ & $26.9 \%$ & $15.4 \%$ & $0.0 \%$ & $11.6 \%$ \\
\hline
\end{tabular}

*The top number is the count of respondents selecting the option. The bottom \% is percent of the total respondents selecting the option. 
total number of responses for each problem were not the same). The null Hypothesis (H0) tested was: there is no significant difference across the five different design caused maintainability problems. A non-

parametric method, the Friedman test, was used for determining the difference across different occasions for the same group of people. The descriptive statistics of the five variables are shown in Table 2.

Table 2- Maintainability problems descriptive statistics*

\begin{tabular}{lllllc}
\hline & & & Standard & Minimum & \\
& $\mathrm{N}$ & Mean & Deviation & Value & Maximum Value \\
\hline EqpAccs1 & 23 & $31.5 \%$ & .24094 & .00 & .75 \\
PoorLayout1 & 23 & $33.7 \%$ & .20792 & .00 & .75 \\
SpcLack1 & 23 & $41.3 \%$ & .23366 & .00 & .75 \\
SpcCeil1 & 23 & $53.3 \%$ & .29488 & .00 & 1.00 \\
SpcFilter1 & 23 & $35.9 \%$ & .25922 & .00 & .75 \\
\hline
\end{tabular}

*The variables listed in the first column correspond to variable of occasions in Table 1.

Table 3- Friedman test mean ranks

\begin{tabular}{lc}
\hline & Mean Rank \\
\hline EqpAccs1 & 2.48 \\
PoorLayout1 & 2.70 \\
SpcLack1 & 3.24 \\
SpcCeil1 & 3.76 \\
SpcFilter1 & 2.83 \\
\hline \multicolumn{2}{|c}{ Table 4- Friedman test statistics } \\
N \\
Chi-Square & 23 \\
df & 14.844 \\
Asymp. Sig. & 4 \\
\hline
\end{tabular}

The 23 respondents rated all of the five problems listed in the questionnaire, the mean values of the frequency is $31.5 \%$ for lack of equipment accessibility, $33.7 \%$ for poor design of equipment layout, $41.3 \%$ for lack of adequate space in mechanical room, and $35.9 \%$ for limited space of AHU filter access. The lack of space designed in the ceiling to contain MEP systems is the most frequently occurring problem with an average frequency of $53.3 \%$.

As shown in Table 4, the significance level is 0.005 which is less than 0.05 . The results of this Friedman Test indicate that there are statistically significant differences in frequency across the five different maintainability problems. The significant difference is somewhere among the five variables. From Table 3, the lack of space designed in the ceiling to contain MEP systems is the most frequently occurring problem, followed by lack of adequate space for the mechanical room, limited space for AHU filter access, poor design of equipment layout, and lack of equipment accessibility.

\section{DISCUSSION OF SURVEY RESULTS}

The BIM-assisted facility management survey had no responses from civil Engineers, structural engineers, structure designers and fabricators, MEP subcontractors, MEP manufacturers nor did MEP suppliers respond to this survey, although there were such companies in the pool. The absence of these organizations could be meaningful. First of all, these groups may not have opportunities to get involved in BIM or facility management and perhaps they are not interested or familiar with the topic studied. Secondly, cooperation in the AECO industry is still segmented and different stakeholders are working in their own areas without sharing technology and information with others.

The survey results indicated that the industry practitioners believed that maintainability issues should be considered in the design and construction phases and they put forward the efforts to make it 
happen. As shown in Figure 5, 28 of the 32 respondents had considered maintainability in the design and/or construction phases. However, maintainability problems are still frequently happens in facility management practice. As shown in Table 2, the mean value of lack of space in ceiling is more than $50 \%$ of the time. For all the other problems, the mean values were about $30 \%$ of the time. These results indicate that even if maintainability has been more or less considered in the earlier phase, with current technology in use, it cannot effectively predict the maintainability issues that would happen in FM phase. Better practices and technologies are needed to carry knowledge from the operation phase to the design and construction phases to better implement the design for maintenance (D4M) rules.

\section{CONCLUSIONS AND FUTURE RESEARCH}

BIM has changed the way the AEC industry communicates and cooperates. Knowledge sharing between the facility management and design professionals has become possible with BIM. BIM technology has been used effectively in the design and construction phases. There is a need to expand BIM beyond the design and construction phases and to consider using BIM for facility management such as in maintenance activities. However, the research on BIM use for facility management is lagging behind the study of BIM in design and construction phases. This research investigated the current industry application of BIM for facility management by a questionnaire.

Maintenance costs, although the largest cost over a building's life cycle, are currently rarely considered in the early design phase. Some design errors that make maintenance activities impossible to perform are always hard to visualize in the design phase. As the next advancement for Facility Management (FM), design for maintenance (D4M) should be considered in the early design phase.

This study is a first effort in bridging the gaps between the design, construction and facility management phases in the AECO industry. There are several areas that need more future research. First of all, from the survey results, there are a lot of other issues reported by the respondents such as vandalism, commissioning, auditing, and lack of guidelines for owners, legal problems, which need further study and which are important for realizing the cooperation and sharing of information among different parties of AECO projects. These problems are not covered in this study but are definitely worth addressing in the future research. Secondly, the design defects that are not maintenance friendly need to be collected from the facility management phase in order to avoid similar design problems in future projects. The problem identified in this research is only the tip of the iceberg. A comprehensive non-maintenance friendly design database needs to be built and made available to the designers.

References:

Arditi, D., and Nawakorawit, M. (1999a). "Designing buildings for maintenance: designers' perspective." Journal of Architectural Engineering, 5, 107-116.

Arditi, D., and Nawakorawit, M. (1999b). "Issues in building maintenance: Property managers' perspective." Journal of Architectural Engineering, 5, 117-132.

Bröchner, J. (1996). "Feedback from Facilities Management to Design and Construction-Systems Issues." The Organization and Management of Construction: Shaping Theory and Practice, E \& FN Spon, London, 238246.

Bröchner, J. (2003). "Integrated Development of Facilities Design and Services." Journal of Performance of Constructed Facilities, 17(1), 19-23.

Cotts, D. G., Roper, K. O., and Payant, R. P. (2010). The facility management handbook, 3rd Edition., AMACOM, New York.

Jaunzens, D., Warriner, D., and Garner, U. (2001). Applying facilities expertise in building design, BRE, Bracknell, UK.

Jensen, P. (2008). "Integration of Considerations for Facilities Management in Design." Design Management in the Architectural Engineering and Construction Sector: CIB W096 Architectural Management \& TG49 Architectural Engineering, 191-199.

Erdener, E. (2003). "Linking programming and design with facilities management." Journal of Performance of Constructed Facilities, 17(1), 4-8.

FM:Systems (2010). "FM:Systems offers powerful software products for facilities and real estate professionals: the FM:Interact Workplace Management suite." <http://www.pdssb.com.my/index.php/products-solutions/fmsystems.html >. (February 15, 2012). 
FitzGerald, A. (2001). "Design for Maintainability (DFM)." START, 8(4).

Foster, B. (2011a), BIM for Facility Management: Design for Maintenance Strategy. Journal of Building Information Modeling, Spring 2011, 18-19.

Gallaher, M. P., O'Connor, A. C., Dettbarn, J. L., and Gilday, L. T. (2004). "Cost Analysis of Inadequate Interoperability in the U.S. Capital Facilities Industry." NIST GCR 04-867 National Institute of Standards and Technology, Gaithersburg, Maryland.

Jaunzens, D., Warriner, D., and Garner, U. (2001). Applying facilities expertise in building design, BRE, Bracknell, UK.

Luthra, A. (2010). "Implementation of Building Information Modeling in Architectural Firms in India." thesis, presented to Purdue University-Main Campus, West Lafayette, IN,. in partial fulfillment of the requirements for the degree of Master of Science

Mohammed, M. A., and Hassanain, M. A. (2010). "Towards Improvement in Facilities Operation and Maintenance through Feedback to the Design Team." The Built \& Human Environment Review, 3, 72-87.

Pati, D., Park, C., and Augenbroe, G. (2010). "Facility Maintenance Performance Perspective to Target Strategic Organizational Objectives." Journal of Performance of Constructed Facilities, 24(2), 180-187.

Qi, J., Issa, R., Hinze, J., and Olbina, S. (2011). "Integration of Safty in Design through the Use of Building Information Modeling." Proceedings of the 2011 ASCE International Workshop on Computing in Civil Engineering, Miami, 698-705.

Shen, W., Hao, Q., Mak, H., Neelamkavil, J., Xie, H., Dickinson, J., Thomas, R., Pardasani, A., and Xue, H. (2010). "Systems integration and collaboration in architecture, engineering, construction, and facilities management: A review." Advanced Engineering Informatics, 24(2), 196-207. 